\title{
O mapeamento participativo como metodologia de análise do território
}

Participatory mapping as analysis methodology of the territory

\author{
C. N. da Silva*; C. C. Verbicaro \\ Universidade Federal Do Pará - Campus do Guamá, CEP: 66075-110 - Belém, PA, Brasil. \\ *cnsgeo@yahoo.com.br
}

(Recebido em 01 de maio de 2016; aceito em 09 de maio de 2016)

\begin{abstract}
A cartografia participativa, diante de um novo paradigma de ciência, apoiada na tecnologia computacional pode se tornar uma importante ferramenta para analisar as diversas territorialidades do espaço geográfico, territorialidades essas baseadas no cotidiano de quem vive e habita um determinado território. Por meio do mapeamento participativo como metodologia de análise do território, este artigo pretende essencialmente dialogar com essa categoria, entendendo o território de forma (I) material, baseado nas relações do sujeito nessa determinada fração do espaço. Diante dessa perspectiva, serão apresentadas as principais metodologias de mapeamento participativo disponíveis para os pesquisadores. Nesse sentido, após a apresentação das metodologias serão feitas recomendações que podem servir às práticas de mapeamento participativo, que traduzirão as complexidades das ações sociais que o homem realiza no espaço, levando a utilização do mapa como instrumento de lutas e representação social.
\end{abstract}

Palavras-chave: Território, Metodologia de Análise, Mapeamento Participativo.

Participatory mapping, facing a new paradigm of science, based on computer technology, can become an important tool to analyze the various territoriality of geographical space, and these territoriality are based on the daily life of those who live and inhabit a given territory. Through participatory mapping as the territory analysis methodology, this article seeks essentially to dialogue with this category, understanding the territory of form (I) material, based on the relationships of the subject on that particular fraction of the space. Given this perspective, will be presented the main methods of participatory mapping that are available to researchers. In this sense, after the presentation of methodologies, recommendations will be made that can serve to the participatory mapping practices that translate the complexities of social action that man performs in space, leading to use the map as a tool of struggle and social representation. Keywords: Territory, Analysis Methodology, Participatory Mapping.

\section{INTRODUÇÃO}

A partir da década de 1970 várias conferências e discussões surgiram com debates sobre a temática ambiental. No ano de 1972, aconteceu em Estocolmo (Suécia) a primeira Conferência das Nações Unidas sobre o Desenvolvimento e o Meio Ambiente. Essa conferência é extremamente importante pois foi o primeiro grande encontro internacional com representantes de diversas nações, para a discussão dos problemas ambientais e a relação entre desenvolvimento e meio ambiente. Outro grande marco desse movimento é a ECO-92, em que as ONGs (organizações não governamentais) se tornaram o termo da moda e se afirmaram como espaço de participação da sociedade civil organizada [1].

Um novo paradigma para a interpretação do tema ambiental na contemporaneidade foi instaurado, norteando a busca do desenvolvimento econômico atrelado à equidade social e à preservação ambiental, influenciando os movimentos sociais [2]. Diante desse quadro, várias ONGs, universidades e outros agentes envolvidos no desenvolvimento e planejamento relacionado à questão ambiental passaram a promover o engajamento das comunidades na tomada de decisões. Esses movimentos fomentaram a criação de diversas metodologias participativas, que visavam capacitar as pessoas a expressar suas condições de vida e 
proporcionar um planejamento de suas ações.

Chambers [3] destaca que de todos os métodos de desenvolvimento participativos já adotados, adaptados e aplicados no contexto do desenvolvimento, a cartografia participativa tem sido a mais utilizada. O seu principal atributo está em concentrar e fornecer as habilidades e competências para que os membros da comunidade elaborem seus próprios mapas, a partir da capacitação e supervisão feita por facilitadores, assim como para representarem o conhecimento espacial dos mesmos, garantindo que determinem a posse dos mapas. Esses mapas podem se tornar uma ferramenta de atuação, que possibilita à comunidade representar os fenômenos socioeconômicos e ambientais de suma importância para o bom desempenho e para o planejamento de ações conjuntas entre comunidades, instituições públicas e privadas [4].

Segundo o International Found for Agricultural and Devolopment [5], existe um número crescente de iniciativas que utilizam o mapeamento participativo pelo mundo. Esses mapeamentos possuem temas diversos, como: mapeamento cultural, mapeamento de planejamento do uso da terra, manejo dos recursos naturais, mapeamento de conflitos e ameaças e mapeamento das territorialidades. No Brasil, podemos destacar três experiências inaugurais dessa metodologia: 1) o mapeamento que deu base ao planejamento em Reservas Extrativistas; 2) o conjunto de iniciativas conhecidas como "Guerra dos Mapas" em Carajás; 3) os projetos socioambientais na Amazônia brasileira [6].

Este trabalho apresenta uma discussão preliminar sobre o uso de algumas das propostas metodológicas que podem ser utilizadas para se analisar as diferentes territorialidades e os diferentes atores e como eles se distribuem no território, tendo como metodologia de análise territorial o mapeamento participativo. Para tanto, são resumidos alguns conceitos básicos e alternativas metodológicas para se oferecer algumas recomendações e conclusões provisórias. Vale ressaltar que este artigo faz parte de um projeto maior, que visa, entre outras coisas, testar em campo as metodologias apresentadas a seguir, com o intuito de subsidiar estudos futuros.

\section{MATERIAL E MÉTODOS}

Este trabalho busca elucidar a respeito dos aspectos metodológicos do uso do mapeamento participativo em pesquisas científicas, a partir da análise de diferentes tipos de aplicações, resultando em uma série de recomendações que podem servir às práticas de mapeamento participativo, que traduzirão as complexidades das ações sociais que o homem realiza no espaço, levando a utilização do mapa como instrumento de lutas e representação social. Para isso, foram necessárias pesquisas bibliográficas e documentais sobre o assunto aludido, que gerou uma série de discussões preliminares a respeito das técnicas existentes, em que foram identificados os prós e contras de cada método de aplicação (mapa mental, mapeamento com base cartográfica, mapeamento com imagens de sensoriamento remoto e mapeamento com uso de SIG), que dependem diretamente do que se quer mapear.

No debate teórico percebeu-se a necessidade de trabalhar com autores diversos que tratam da temática deste trabalho e tem nas categorias território e territorialidade o principal enfoque. E, a partir desta opção teórica, recorreu-se à pesquisa de campo, com registros fotográficos, e ao levantamento e sistematização dos dados em laboratório de geoprocessamento (para a digitalização, vetorização e elaboração de mapas sínteses), que possibilitaram o reconhecimento das formas geográficas e da realidade do que foi mapeado em campo. Após o trabalho de campo e da análise em laboratório, todo o material produzido com a aplicação das técnicas de mapeamento participativo refletirão em uma série de outros textos que tem na metodologia testada o objeto principal. 


\section{RESULTADOS E DISCUSSÕES}

\subsection{A cartografia participativa como proposta metodologica}

Para a realização do mapeamento participativo é necessário antes de tudo escolher o público alvo. Buscar, recrutar e conversar com pessoas que são ligadas à localidade desejada, e que tenham a vivência do cotidiano e um vasto conhecimento das características do território que será mapeado. Por exemplo, normalmente em localidades onde a pesca é predominante, os pescadores têm informações preciosas sobre todos os territórios de pesca [7]. Após essa seleção deve-se ter uma primeira conversa com todos que participarão do mapeamento, explicando passo a passo como será a confecção dos mapas e quais os objetos que eles utilizarão para a plotagem de informações. Logo, se deve deixar bem claro que os mapas serão demarcados por eles e que devem demarcar seus locais de convívio, de lazer, trabalho e até de conflitos/problemas (ambientais, sociais, etc.).

Para Gorayeb [8] a participação na construção do mapa é uma forma de fortalecer a mobilização de grupos que se apropriam de uma ferramenta, a cartografia, para uso de seus interesses. E a participação dos grupos mobilizados não se restringe à confecção dos mapas, pois a partir do processo de construção destes mapas as demandas são fortalecidas e há o reconhecimento de direitos, o que pode direcionar a estratégias de atuação coletiva. Cada situação de mapeamento tem seus próprios objetivos. Uma classificação possível, entre tantas outras, dos objetivos presentes nos processos de mapeamento participativo realizados no Brasil, pode ser a seguinte: a) busca por legitimidade; b) busca por informações mais precisas e; c) busca pelo fortalecimento da mobilização dos grupos [8].

O IFAD [5] faz uma breve definição de mapeamento participativo, tal como vemos a seguir: O mapeamento participativo é a criação de mapas pela comunidade local em muitos casos envolvendo organizações de suporte como o governo (em diversos níveis), organizações não governamentais (ONG), universidades e outros agentes envolvidos no desenvolvimento e no planejamento relacionado com a terra. Trata-se de um processo de produção de mapas que intenta tornar visível a associação entre terra e comunidades locais ao usar a linguagem comumente entendida e reconhecida da cartografia [5].

Existem vários procedimentos para executar a cartografia participativa, tais como o mapa mental, mapeamento de transecto, de maquetes e recentemente o mapeamento participativo que tem utilizado também técnicas cartográficas digitais, incluindo o Global Positioning Systems (GPS), fotografias aéreas e imagens de sensoriamento remoto, Sistema de Informação Geográfica (SIG) e outras tecnologias baseadas na cartografia digital [9]. Assim, foram selecionados quatro dos procedimentos citados acima para discutir e avaliar seus prós e contras diante do objetivo do que se quer mapear.

\subsection{O mapa mental (croqui)}

O croqui é uma representação de cunho cartográfico, embora não necessite de escala e nem de referência formal (coordenadas geográficas). Ou seja, é um tipo de mapa cognitivo ou mental que é confeccionado sem uma convenção regulamentada por órgão oficial, e que depende da percepção que seu elaborador tem do meio que o circunda, por isto não possui rigores científicos para sua concepção, conforme mostra a Figura 1. 


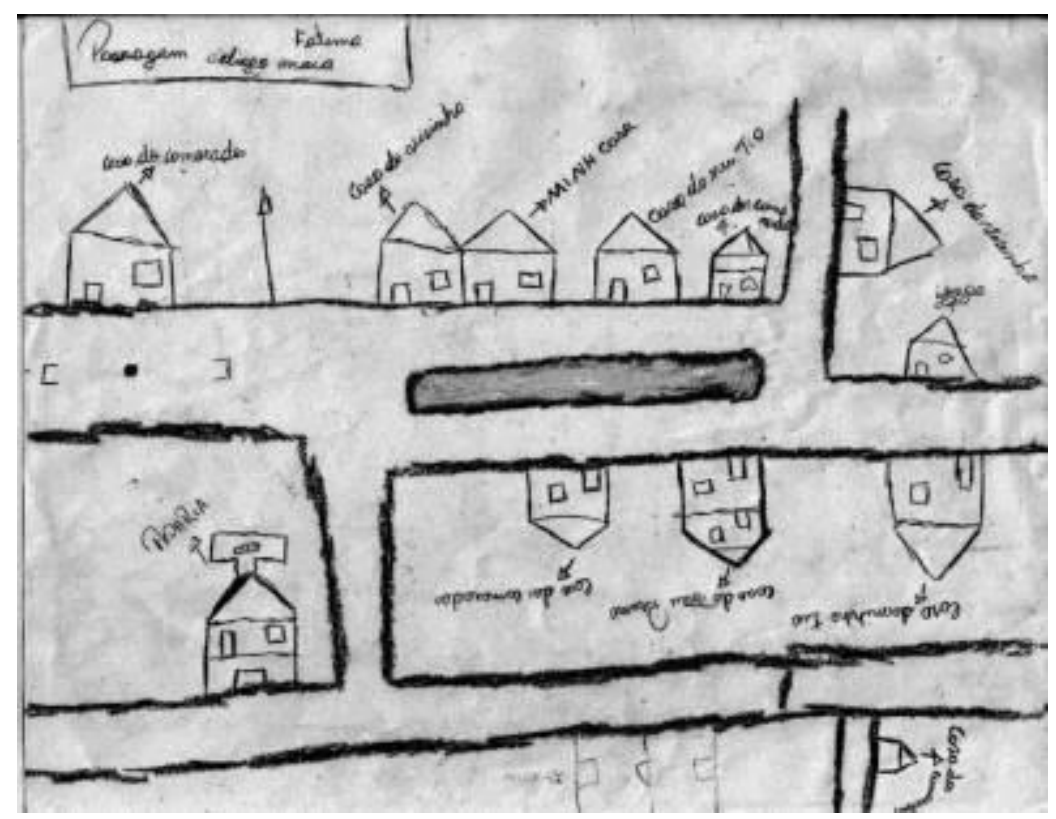

Figura 1: Mapa mental do local de origem do aluno 1 (Exemplo de mapa mental) Fonte: Oliveira Neto; Brito Neto; Lima [10]

Pela visualização da Figura 1, pode-se perceber que não há rigor cartográfico para a elaboração do croqui, com a exigência de todos os elementos básicos do mapa (legenda, escala, orientação, título, etc.), mas pede-se ao elaborador a aproximação da representação espacial com o que se observa na realidade, utilizando símbolos que devem ser criados pelos participantes, mas compreendidos por outros leitores. Lima e Costa [11] em seu trabalho analisam a representação espacial elaborada a partir de técnicas de cartografia social utilizadas por crianças e adolescentes ribeirinhas/quilombolas da Amazônia, como apresentado na Figura 2.

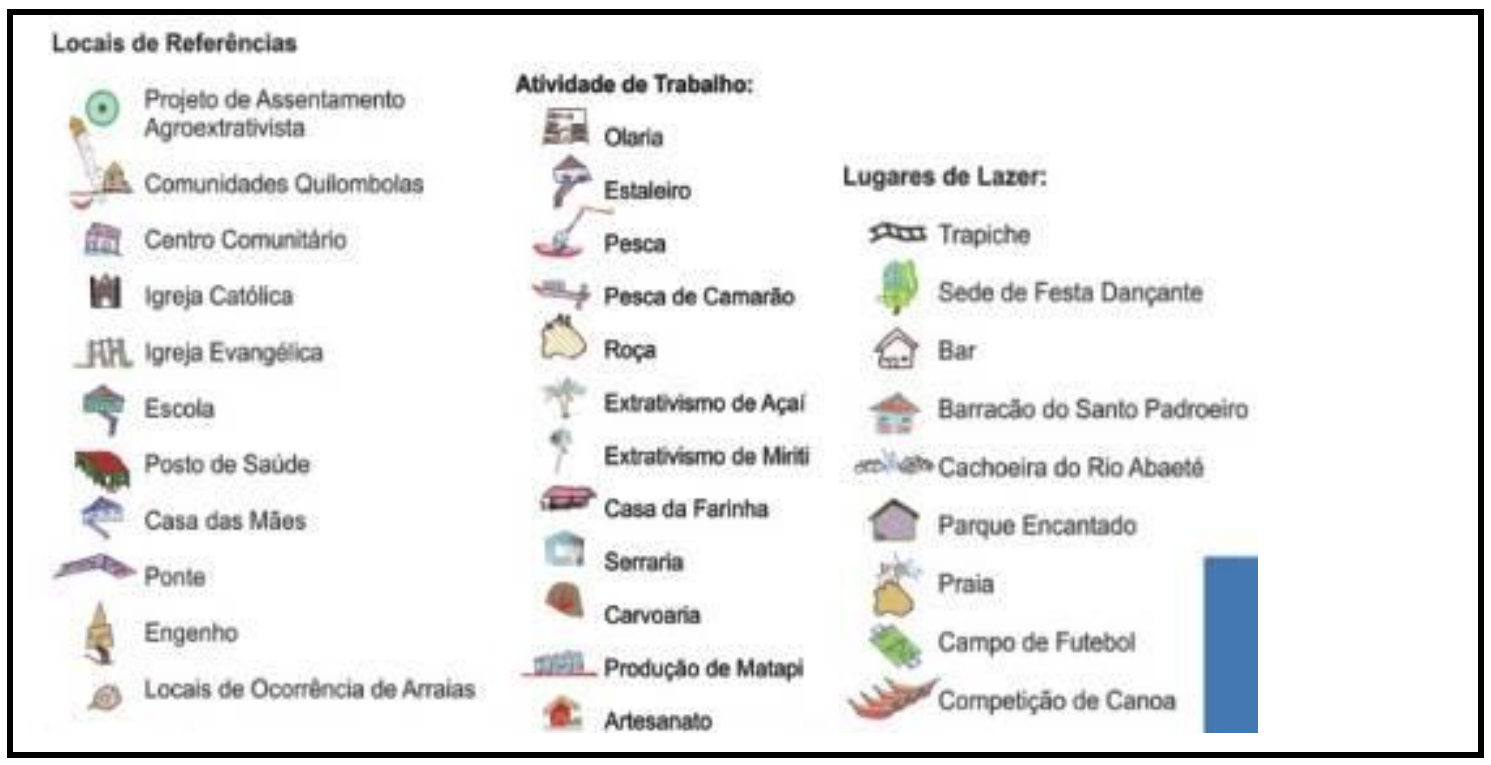




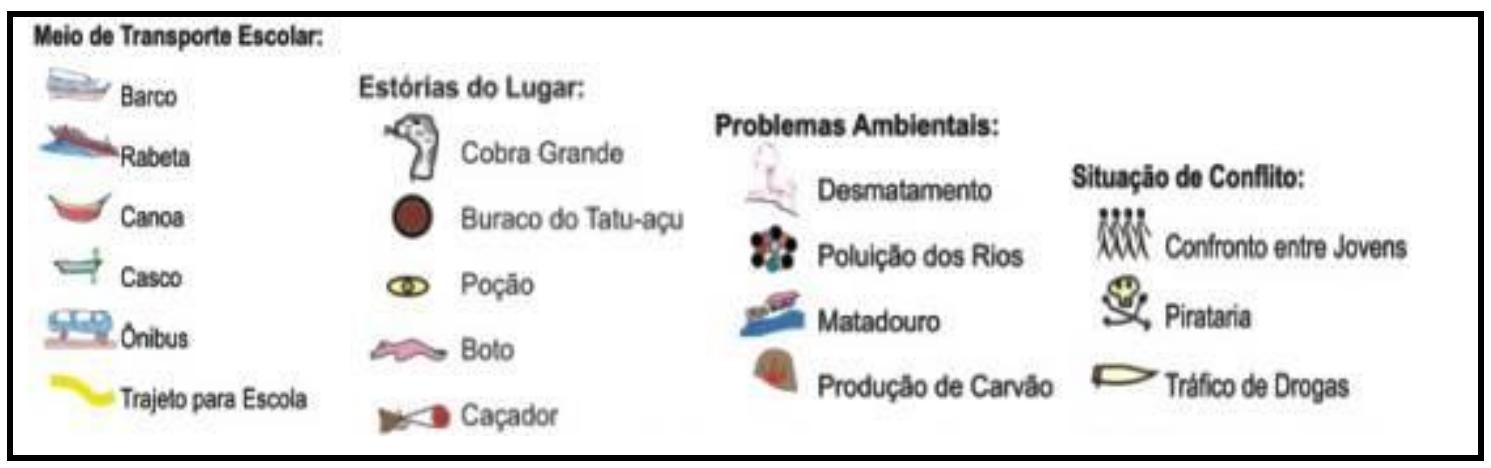

Figura 2: Legenda do Mapa das crianças e adolescentes com os temas e seus respectivos pontos de referências político-sócio-culturais

Fonte: Lima; Costa [11]

Esse tipo de mapeamento pode ser a chave para a comunidade identificar suas principais formas de representação da realidade, utilizando apenas folhas grandes de papel (tamanho A1, por exemplo) e canetas coloridas. Neste procedimento, os participantes do mapeamento têm a chance de escolher que materiais utilizar e que itens acham relevantes para representar nos mapas, avaliando quais as formas e como elas serão desenhadas, podendo a sua variação estar diretamente ligada ao grau de importância dessas feições para a comunidade. O mapa mental não se preocupa em representar medidas exatas, escala consistente e georreferenciada, ele está aberto para interpretação do sujeito sobre sua realidade e dá a chance desse sujeito representá-la [9]. A Figura 3 demonstra a construção de um mapa mental coletivo e/ou comunitário a partir das experiências vividas por membros de uma determinada comunidade:

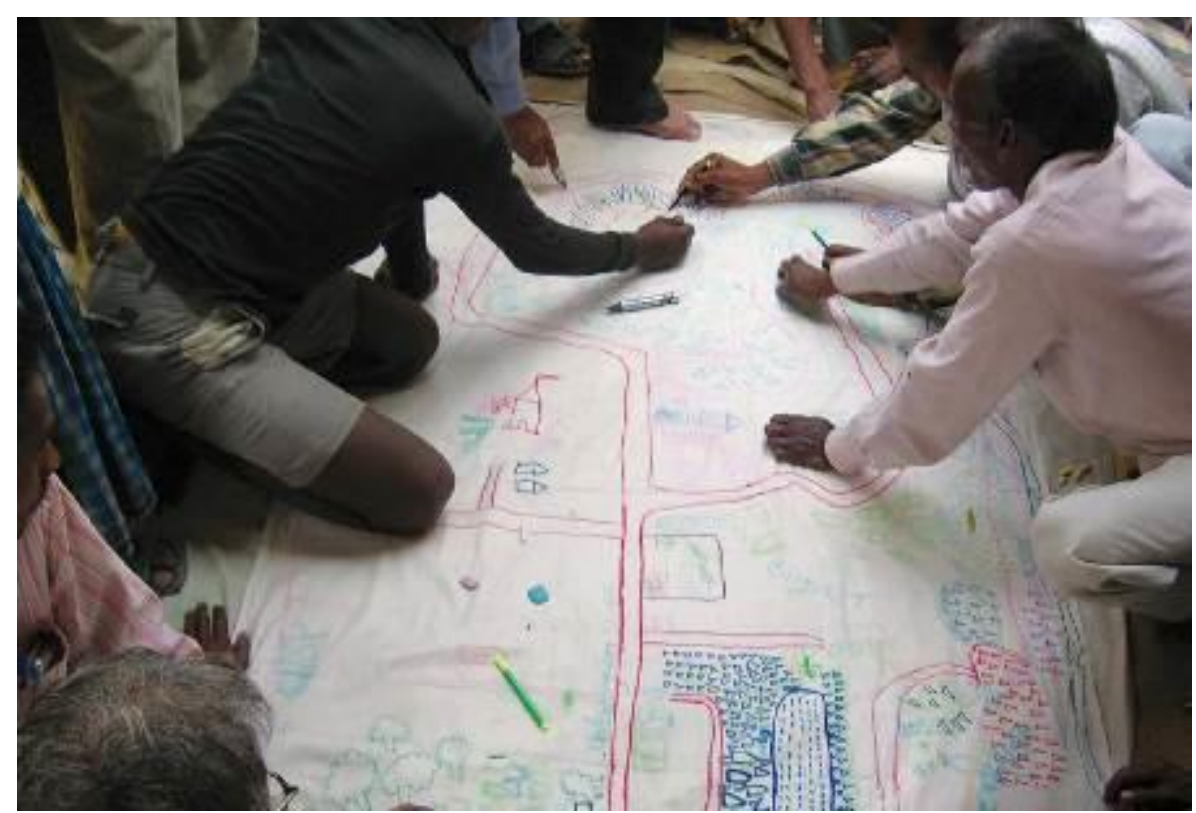

Figura 3: Avaliação participativa do Projeto de empoderamento da comunidade para o acesso à terra, Uttar Pradesh, India

Fonte: IFAD [5]

Assim, segundo IFAD [5], os mapas feitos à mão são bastante utilizados para representar os problemas relacionados ao uso da terra. Eles ajudam a promover uma ampla representatividade dos problemas e eventos que competem à área mapeada, podendo ser úteis para familiarizar a comunidade ao uso do mapa e fornecer aos participantes a oportunidade de utilizar a cartografia como ferramenta de planejamento. O próximo método subdivide-se em outros três, e destaca, principalmente, o uso da cartografia digital como ferramenta para a aplicação do mapeamento participativo. 


\subsection{Pgis (participatory gis)}

Consiste num método mais sofisticado, que vincula a tecnologia de SIG (Sistema de Informações Geográficas) à participação da comunidade [9]. Ele está subdividido em três modalidades de aplicação: a) mapeamento com bases cartográficas; b) mapeamento com imagem de sensoriamento remoto; c) mapeamento com o uso de SIG. Essas técnicas podem resultar em diferentes produtos, portanto, cabe ao pesquisador avaliar suas condições e o objetivo da pesquisa e eleger um ou dois procedimentos para representar o objeto e/ou fenômeno de estudo. A seguir, uma breve descrição destas três modalidades:

\subsubsection{Mapeamento com bases cartograficas}

Neste procedimento, uma equipe de facilitadores leva à comunidade um mapa base, contendo algumas informações georreferenciadas como sede municipal e rede hidrográfica, por exemplo. Sobre ele os participantes plotarão a localização da sua comunidade, mapeando as informações que desejam representar, proporcionando uma simbologia adequada de acordo com as figuras selecionadas pelos próprios elaboradores [5]. Neste tipo de mapeamento é importante que o mapa base não influencie enfaticamente as percepções dos mapeadores, não seja tendencioso, para que os participantes não sejam estimulados a representar objetos/fenômenos que não sejam aqueles relacionados as suas próprias experiências.

A Figura 4 mostra a construção de um mapeamento participativo, baseado na plotagem de objetos e fenômenos sobre um mapa base.

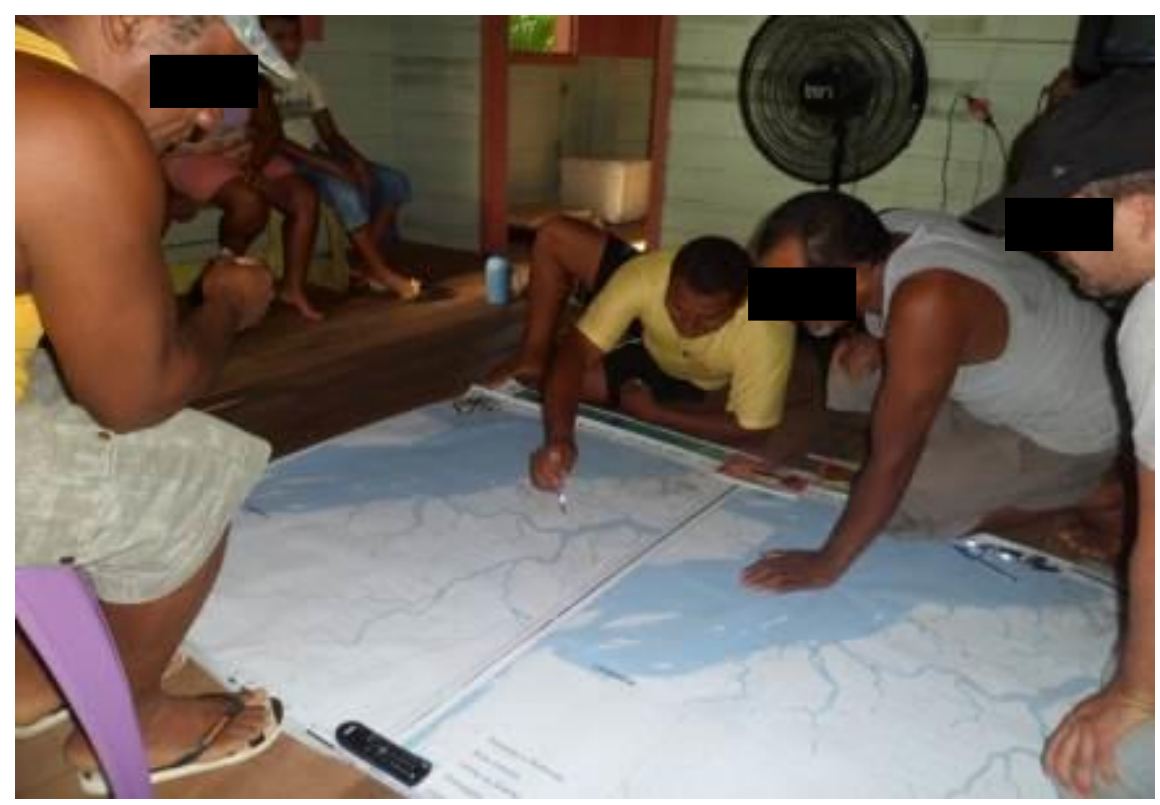

Figura 4: Mapeamento Participativo com a utilização de Mapa-Base Fonte: Pesquisa de campo (2014)

É necessário mostrar a todos os participantes o mapa base do território ocupado. Sugere-se que a apresentação e plotagem de informações se dê com a distribuição dos participantes em grupos, com três ou mais pessoas para que a realização do mapeamento seja diversificada. Após isso, deve-se entregar o mapa base para os grupos juntamente com os lápis/canetas que serão utilizados pelos mesmos. É importante reforçar para os mapeadores que não deverão se importar com erros e/ou a elaboração de desenhos bonitos, mas que sejam compreensíveis, e após, a localização de algum objeto ou fenômeno, o mapeador deve escrever ao lado o seu significado. 
Ao dar início ao mapeamento com o uso dessa modalidade é preciso fazer a monitoria dos grupos para que a confecção dos mapas não seja feita única e exclusivamente por uma só pessoa e sim para que todos participem. Deve-se observar as demarcações e tirar dúvidas dos participantes no decorrer da construção. Logo após, as informações plotadas no mapa deverão ser digitalizadas e georreferenciadas em um software de geoprocessamento ou SIG, para depois serem elaborados os mapas com as informações do mapeamento participativo.

Essa técnica tem um custo relativamente baixo e uma rápida resposta, além de fornecer à comunidade uma representação com precisão razoável e com muita informação do conhecimento territorial. O mapa resultante desse processo pode ser utilizado tanto para determinar dados quantitativos como distâncias e direções.

\subsubsection{Mapeamento com imagem de sensoriamento remoto}

Esta metodologia é realizada primeiramente com a confecção de uma carta-imagem produzida por meio do cruzamento dos dados cartográficos, tais como rede hidrográfica, limites municipais, rede rodoviária, pontos de GPS (Global Positioning Systems) da comunidade (escola, centro comunitário e igreja) e imagens de sensoriamento remoto de boa resolução espacial. Silva [12] compreende que a seleção das imagens de sensoriamento remoto dependerá da escala geográfica do território representado e do tamanho do papel que será o suporte da imagem impressa. E para melhor visualização dos objetos contidos na imagem apresentada é necessário a impressão em uma dimensão adequada (cerca de $1 \mathrm{~m} \mathrm{x} \mathrm{1,5} \mathrm{m),} \mathrm{que} \mathrm{é} \mathrm{levada} \mathrm{até} \mathrm{os}$ participantes para plotagem de informações direto na folha, como mostrado na Figura 5.

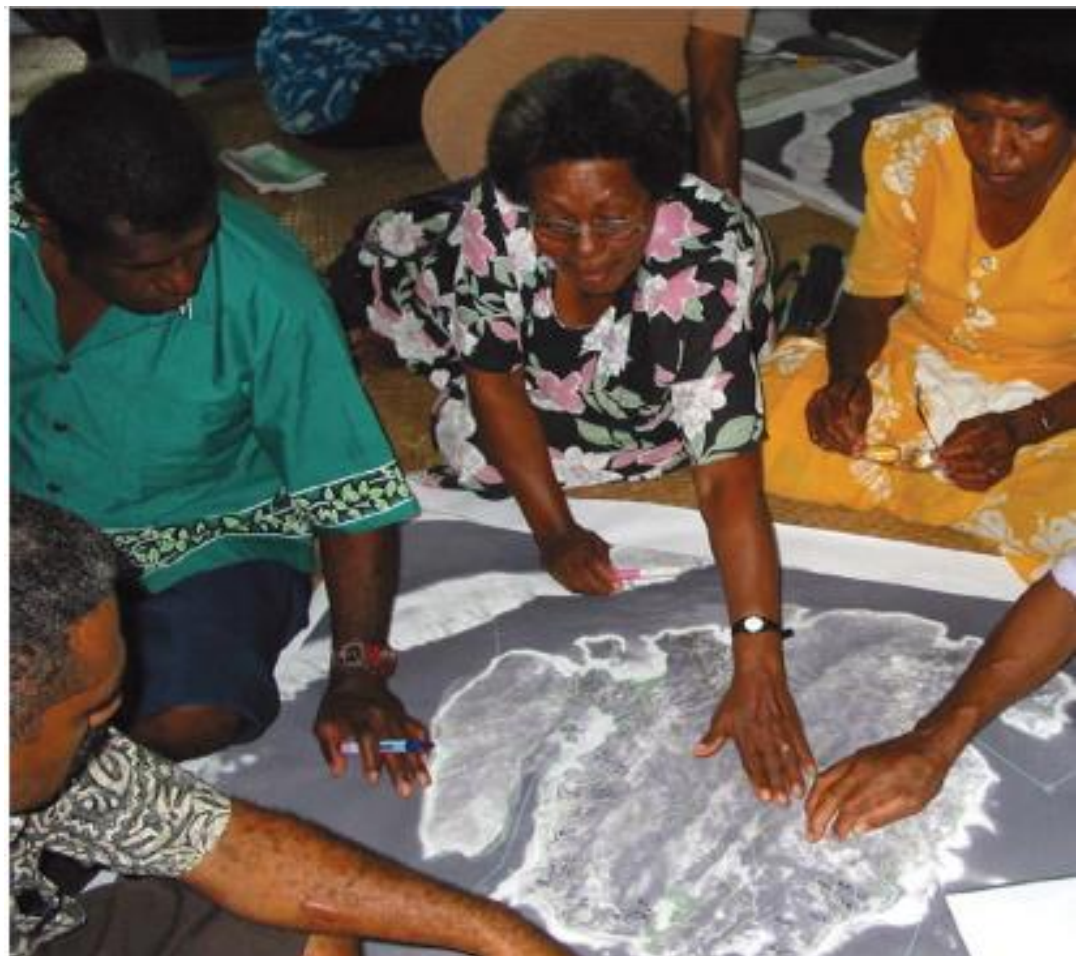

Figura 5: Mapeamento Participativo utilizando uma imagem de sensoriamento remoto, Fiji Fonte: IFAD [5]

Durante o mapeamento participativo os moradores locais podem desenhar por cima de um plástico ou na própria carta-imagem os objetos a serem mapeados. O objetivo é proporcionar aos participantes uma visualização da densidade das áreas verdes e outros objetos e fenômenos do território, com a finalidade de identificar e classificar, com base na geometria e no comportamento espectral das feições sintéticas, bem como, a partir da percepção dos participantes do mapeamento, as áreas degradadas, tais como roçados, fazendas, áreas de 
pastagens e outros, subsidiando a definição de áreas para usos futuros e geração de mapas temáticos.

\subsubsection{Mapeamento com uso de SIG}

Neste mapeamento o procedimento adotado consiste em uma familiarização dos mapeadores com a informática e com os softwares que oferecem a opção SIG, treinando alguns atores sociais na operação dessas ferramentas (Figura 6). Essa metodologia tem o intuito de democratizar esse tipo de tecnologia, no entanto, é considerada de custo elevado e complexo, sendo em maioria utilizada por especialistas em geoprocessamento. Outro fator que impossibilita a utilização dessa técnica são as contínuas atualizações dos softwares que demandam um novo e contínuo treinamento.

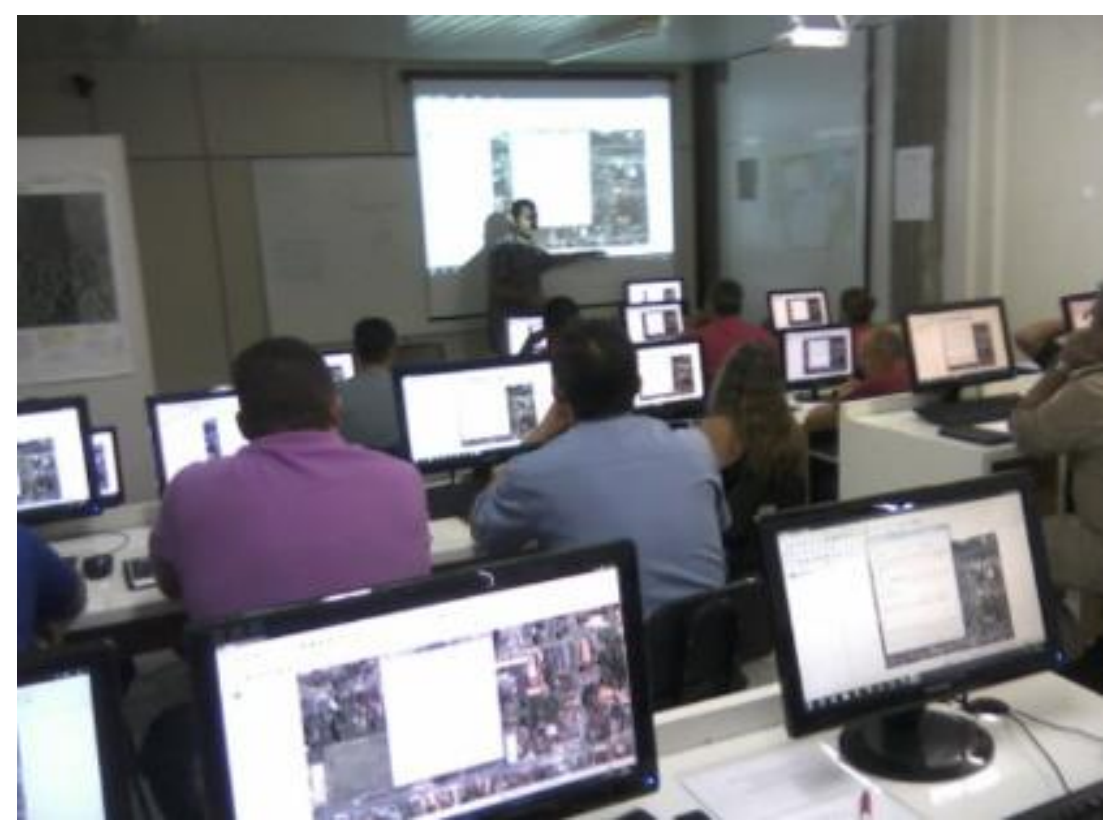

Figura 6: Capacitação em Geoprocessamento e SIG no Laboratório de Análise da Informação Geográfica, da Universidade Federal do Pará (LAIG/UFPA)

Fonte: Silva et al [13]

Durante a execução da capacitação em SIG no laboratório é sempre importante lembrar que apesar dos avanços que se observa na cartografia, desde os tempos antigos até hoje, os conceitos, categorias e os elementos que representam a esfericidade do planeta e que compõem um mapa foram pouco alterados, ou seja, as técnicas de redução do espaço real para a folha de papel (escala), de manutenção de formas ou distâncias para representação no plano/papel (projeção), o título, a orientação e a legenda ainda são elementos que não podem faltar para se entender o que um mapa quer mostrar $[12,14]$. Então, independente de saber manusear um software de geoprocessamento para se construir um mapa, é necessário entender que por trás daquelas funções do programa existem uma série de técnicas e conhecimentos que foram construídos durante séculos $[15,16]$ e devem ser compreendidos para que a atividade de construção do produto cartográfico não se transforme apenas em uma prática de "apertar botões".

A disponibilidade de laboratórios adequados à capacitação em mapeamento participativo é uma outra dificuldade encontrada para o uso dessa metodologia (Metodologicamente, a aplicação da metodologia do mapeamento participativo pode ser utilizada em diversos espaços, onde se pretende o reconhecimento do território de qualquer tipo de comunidade, desse modo, existem estudos que abordam o uso desta ferramenta em áreas urbanas [17], áreas rurais [4], em comunidades de pescadores [7], entre outras). Pois, além do laboratório estar disponível, o transporte e alimentação devem ser garantidos aos participantes no momento da capacitação, o 
que torna essa opção significativamente dispendiosa. Nas outras opções de mapeamento participativo o pesquisador deve também capacitar os participantes no uso do mapa antes da plotagem das informações, contudo, a apresentação do geoprocessamento não é enfatizada como no uso do SIG. Todavia, a opção por uma modalidade ou outra vai depender de diversos fatores, que refletirão diretamente na participação e nos resultados alcançados pela pesquisa, para isso, elencaremos algumas recomendações que podem ser seguidas na aplicação do mapeamento participativo como metodologia de análise territorial.

\subsection{Recomendações para o mapeamento participativo}

Como apresentado, cada tipo de modalidade possui procedimentos metodológicos com pontos positivos e pontos negativos, cabe ao pesquisador verificar suas condições e visualizar o objetivo do seu trabalho para escolher qual a melhor forma para cartografar a realidade estudada. O Quadro 1 apresenta de forma sistematizada os pontos fortes e fracos de cada modalidade de aplicação de mapeamento participativo aqui apresentado.

\section{Quadro 1: Matriz de ferramentas de mapeamento participativo}

\begin{tabular}{|c|c|c|}
\hline 'écnicas & Pontos Fortes & Pontos Fracos \\
\hline 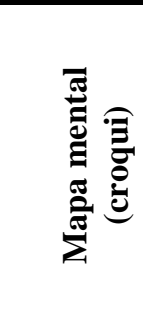 & $\begin{array}{l}\text { 1. Custo baixo. } \\
\text { 2. Independe de tecnologia. } \\
\text { 3. Útil para ser usado por não expert. } \\
\text { 4. Rende vários detalhes sobre a realidade. } \\
\text { 5. Gera rapidamente resultados, aplicação } \\
\text { fácil. } \\
\text { 6. Boa replicação em nível comunitário. }\end{array}$ & $\begin{array}{l}\text { 1. Os resultados não são } \\
\text { georreferenciados. } \\
\text { 2. Dificuldade na transposição de um } \\
\text { mapa de escala. } \\
\text { 3. A falta de precisão dá pouca } \\
\text { credibilidade nas esferas governamentais. } \\
\text { 4. Não é viável quando precisa mensurar } \\
\text { dados quantitativos. }\end{array}$ \\
\hline 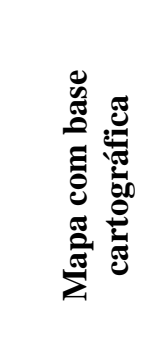 & $\begin{array}{l}\text { 1. Custo baixo. } \\
\text { 2. Ferramenta rápida (se comparada com } \\
\text { outros métodos participativos). } \\
\text { 3. Independente de tecnologia. } \\
\text { 4. Boa representação do conhecimento } \\
\text { local. } \\
\text { 5. Pode ser utilizado para mapear dados } \\
\text { quantitativos, como área, distância e } \\
\text { direções. }\end{array}$ & $\begin{array}{l}\text { 1. Precisão razoável. } \\
\text { 2. Para o entendimento dos protocolos } \\
\text { cartográficos é necessário um treinamento. } \\
\text { 3. É mais complexo que o mapa mental. }\end{array}$ \\
\hline 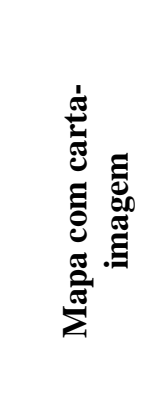 & $\begin{array}{l}\text { 1. Útil para mapear áreas grandes e de } \\
\text { difícil acesso. } \\
\text { 2. Proporciona uma ampla visão do uso e } \\
\text { cobertura do solo da comunidade. } \\
\text { 3. Custo baixo e fácil acesso de imagens } \\
\text { disponíveis para download na internet. } \\
\text { 4. Pode oferecer à comunidade uma } \\
\text { perspectiva da sua área que talvez eles não } \\
\text { tenham experimentado antes. } \\
\text { 5. Fácil interpretacão das feicões. }\end{array}$ & $\begin{array}{l}\text { 1. Não possuem legendas, os comunitários } \\
\text { terão que interpretar os objetos. } \\
\text { 2. Algumas imagens são difíceis de } \\
\text { interpretar; imagens que possuem uma } \\
\text { melhor resolução são mais complicadas de } \\
\text { conseguir na internet gratuitamente, } \\
\text { geralmente as imagens disponíveis são de } \\
\text { resolução espacial de } 30 \text { metros, } \\
\text { inadequadas para serem trabalhadas em } \\
\text { escala local. }\end{array}$ \\
\hline 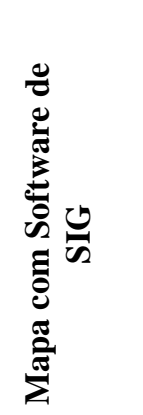 & $\begin{array}{l}\text { 1. Bom para representar informações locais } \\
\text { georreferenciadas. } \\
\text { 2. Usa ferramentas de análise espacial para } \\
\text { criar um sofisticado banco de dados com } \\
\text { informações quantitativas da área. } \\
\text { 3. A comunicação das informações } \\
\text { representadas é de boa transmissão. }\end{array}$ & $\begin{array}{l}\text { 1. Dificuldade de aprendizado de } \\
\text { conhecimentos computacionais. } \\
\text { 2. Requer uma atualização contínua de } \\
\text { treinamento para acompanhar as } \\
\text { atualizações de softwares periódicas. } \\
\text { 3. Muito caro para a maioria dos } \\
\text { participantes. } \\
\text { 4. O treinamento requer o entendimento } \\
\text { dos equipamentos e dos protocolos } \\
\text { cartográficos. }\end{array}$ \\
\hline
\end{tabular}


Segundo Chambers [3], independentemente da forma e dos meios para executar o mapeamento participativo (no chão, no papel ou em SIG) a natureza dos resultados dependerá das atitudes e comportamento dos facilitadores e de quem controla o processo, influenciando na tomada de decisão desses resultados. A partir do que foi apresentado, recomendamos alguns procedimentos na utilização do mapeamento participativo como metodologia de análise do território, que podem auxiliar no processo de aplicação da metodologia em campo e na elaboração do mapa síntese com as informações representadas.

- Para uma boa aplicação da metodologia, um bom relacionamento do pesquisador com a comunidade é a chave para o sucesso. Este relacionamento deve conter três ingredientes importantíssimos: transparência, tempo e confiança. Caso contrário, o processo de mapeamento participativo poderá se tornar improdutivo ou até mesmo inviável. Portanto, é necessário manter-se transparente na abordagem, sendo aconselhável promover reuniões para definir e explanar a metodologia. Deve-se também utilizar uma linguagem simples, clara, criativa e que envolva todos os participantes.

- Outro ponto que vale ressaltar é a importância do planejamento das atividades. O pesquisador deverá verificar e selecionar os conteúdos a serem representados (áreas de lazer, conflitos, comunitárias/coletivas, festas, religião, etc.), bem como os objetivos, metodologias de coleta de informações, materiais e equipamentos necessários, além de textos de apoio e a definição do público-alvo que participará da elaboração dos mapas.

- A realização de reuniões coletivas com os indivíduos pode ser eficaz se tiver além da elaboração dos mapas outro objetivo, como, por exemplo, as reuniões de organizações sociais, religiosas ou escolares, que agregam os participantes para a resolução de conflitos ou a discussão de assuntos de interesse coletivo.

- O pesquisador deve possuir o conhecimento prévio sobre o assunto que será coletado e sobre as características gerais da região pesquisada, pois é necessário o conhecimento antecipado dos costumes, principais ocupações dos moradores, meios de transporte, alimentação, etc., para serem debatidos e inquiridos antes do início da coleta de informações. De antemão é importante verificar se os conceitos e categorias (da geografia, por exemplo), discutidos e apresentados para a elaboração dos mapas participativos são aceitos pela comunidade científica, como forma de evitar a indução ao erro e/ou a representação incorreta no mapa gerado.

- Antes de iniciar a aplicação da metodologia, os facilitadores precisam verificar a infraestrutura onde serão realizadas as reuniões, pois é importante possibilitar a participação de todos os moradores que desejam representar cartograficamente suas atividades ou seu modo de vida. É necessária uma apresentação das noções básicas de localização, escala e outros conceitos cartográficos, tudo de forma clara e didática, para enfatizar a importância dessa metodologia como forma de fortalecer a necessidade do mapeamento do território.

- Durante o procedimento de plotagem das informações, a equipe de facilitadores tem como finalidade escutar os comunitários, encorajá-los, realizar perguntas, sondar e, principalmente, não interferir com preconceito de origem, etnia, gênero, religião, idade ou condição socioeconômica, pois a ênfase a esses temas pode gerar novos conflitos, inexistentes antes da aplicação da metodologia participativa.

- A equipe deverá promover, durante a elaboração dos mapas participativos, atividades de inclusão e discussão em grupo, que permitirão aos indivíduos analisar de forma crítica os seus modos de vida e sua participação na comunidade. No decorrer da aplicação do procedimento, os mediadores devem atentar para falta de precisão e diferentes escalas, além de ter cuidado com as generalizações acentuadas. É necessário ter cautela com a influência da visão parcial do pesquisador, pois a visão do entrevistado/mapeador deve ser valorizada e ao transformar os dados em informação, os símbolos utilizados deverão ser reconhecidos por todos os participantes.

- Outro ponto importante que precisa ser executado em campo é a verificação das informações coletadas, uma reambulação, que consiste em identificar e nomear feições conhecidas dos 
moradores. Devido à falta de precisão cartográfica, é necessário verificar as escalas, pois é preciso cuidado com a generalização acentuada, com dados em diferentes escalas. Assim, é recomendada uma acareação das informações coletadas com mais de um morador para evitar informações incorretas ou inverídicas.

- No procedimento de mapeamento com base cartográfica é necessário ter vários mapas base da área estudada, em branco e impressos, para a coleta de diversas informações de sobreposição posterior, com a digitalização e vetorização em software de geoprocessamento. Se a técnica utilizada for o mapeamento com a carta-imagem, devem-se procurar imagens de sensores óticos (coloridas), que apresentem cores e tonalidades percebidas próximas do real, ao contrário de imagens de sensores de micro-ondas (radar), que informam tons de cinza. Todavia, é necessário ter cautela, uma vez que o uso de imagens de sensoriamento remoto são tendenciosas, pois apresentam feições do espaço que podem não ser percebidas e/ou informadas pelos interlocutores.

- O pesquisador deve definir critérios e parâmetros próprios adequados para a comunidade pesquisada, pois o uso de símbolos, ferramentas e outras técnicas são diferenciados, de acordo com a comunidade estudada. Sugere-se construir uma simbologia na própria comunidade, no momento do mapeamento, referindo-se sempre à representação cartográfica da realidade mapeada.

- O pesquisador deverá apresentar o mapa final para as comunidades participantes para a confirmação da veracidade das informações. A disponibilização de diversas cópias do mapa final elaborado para a comunidade deve servir como ferramenta de reconhecimento e reafirmação do uso do território em documentos oficiais, como por exemplo, em planos de manejo ou outros.

Essas recomendações podem servir como suporte ao pesquisador durante a aplicação de técnicas de mapeamento participativo do território. Sabemos que existirão sugestões próprias e outras que o pesquisador encontrará somente em campo. Assim, a aplicação do mapeamento participativo não é uma receita terminada, a ser seguida cegamente. Antes de tudo, é uma metodologia de análise territorial que precisa ser entendida e adequada à realidade em foco.

\section{CONCLUSÃO}

Neste trabalho foi apresentada uma revisão de procedimentos metodológicos baseados no mapeamento participativo, expondo várias modalidades de aplicação, que podem ser utilizadas para diversos fins, analisando os seus prós e contras e qual o melhor aproveitamento de cada técnica, seguindo para recomendações de aplicação das metodologias participativas, baseadas nas experiências anteriores de contato com comunidades rurais. Vale ressaltar que as técnicas apresentadas neste artigo estão sendo avaliadas em campo, em pesquisa que está utilizando o mapeamento participativo para entender as interações e interesses relativos ao uso do território entre os múltiplos atores em suas diferentes formas de apropriação do espaço.

O mapeamento participativo deve ser utilizado como ferramenta para representar como a comunidade percebe o seu território e as características significativas dentro do mesmo. Tais características podem incluir representações dos traços físicos naturais, assim como traços socioculturais conhecidos pela própria comunidade. Podemos refletir que o diferencial do mapeamento participativo está relacionado ao fato em que não se limita a simplesmente representar o desenho geográfico, sendo possível ilustrar importantes conhecimentos sociais, culturais e históricos, incluindo, por exemplo, informações relacionadas à ocupação do uso da terra, mitologia, demografia, grupos étnico-linguísticos, padrões de saúde e distribuição da mesma.

O reconhecimento do ser no/com o território pode possibilitar o empoderamento e a busca de autonomia do sujeito, refletindo em um desenvolvimento territorial e na dinâmica interna da comunidade, podendo se tornar uma alternativa para o processo de busca coletiva de formas viáveis no contexto local, contribuindo para o crescimento e coesão na comunidade, por meio da imposição à sociedade externa do reconhecimento de sua existência e de sua cidadania. A 
ascensão e democratização dos conhecimentos cartográficos podem ser opção para reivindicação de políticas públicas de planejamento e de base para a autogestão nos territórios, utilizando-os para promover uma melhor comunicação com os órgãos públicos, expressando os seus problemas e suas potencialidades. Mostrando que a cartografia pode servir nas práticas territoriais se destacando numa esfera político e social significativa, traduzindo as complexidades das ações sociais que o homem realiza no espaço, utilizando o mapa como um instrumento de luta dos movimentos sociais.

\section{REFERÊNCIAS BIBLIOGRÁFICAS}

1. Scherer-Warren I. Movimentos sociais e participação. In: Sposati, A. et. al. (orgs), Ambientalismo e participação na contemporaneidade. São Paulo: Educ/Fapesp; 2001, p. 41-56.

2. Campos LG. Populações tradicionais, unidades de conservação e mineração: territorialidades e práticas de gestão de recursos naturais - Oriximiná-PA. Rio de Janeiro: UFF; 2009.

3. Chambers R. Participatory mapping and geographic information systems: Whose map? Who is empowered and who disempowered? Who gains who loses? Eletronic Journal on information Systems in Developing Countries. 25 (2): 1-11. Disponível em: http://dev.opendocs.ids.ac.uk/opendocs/bitstream/handle/123456789/84/rc248.pdf?sequence=1. Acesso em: 7 mar 2016.

4. Verbicaro C., Silva, CN. Percepção da distribuição espacial das palmeiras de açaí e miriti ao longo de 20 anos na várzea da Amazônia paraense. Anais do XI Encontro Nacional da ANPEGE. Presidente Prudente, São Paulo; 2015. Disponível em: https:// http://www.enanpege.ggf.br/2015/anais/arquivos/17/485.pdf. Acesso em: 18 mar 2016.

5. Ifad, International Fund for Agricultural Development. Good practices in participatory mapping: a review prepared for the International Fund for Agricultural Development (IFAD). Italy: IFAD; 2009.

6. Acselrad H. (Org.). Cartografia social e território. Rio de Janeiro: IPPUR/UFRJ; 2008.

7. Chaves CMSRS. Mapeamento participativo da pesca artesanal na Baia de Guanabara. 2011. Dissertação (Mestrado em Geografia). Programa de Pós-Graduação em Geografia, Instituto de Geociências, Universidade Federal do Rio de Janeiro; 2011.

8. Gorayeb A. Cartografia social e populações vulneráveis: oficina do eixo erradicação da miséria. 2014. Disponível em: http://www.mobilizadores.org.br/wp-content/uploads/2014/07/CartilhaCartografia-Social.pdf. Acesso em: mar 2016.

9. Rambaldi G., Kyem PK., Mbile P., Mccall M. \& Weiner D. Participatory spatial information management and communication in developing countries. The Electronic Journal on Information Systems in Developing Countries. EJISDC (2006) 25, 1, 1-9. Disponível em: https://www.ejisdc.org/ojs2/index.php/ejisdc/article/viewFile/237/158. Acesso em: 7 mar 2016.

10. Oliveira Neto A, Brito Neto C, Lima SB. O ensino de geografia no contexto socioeducativo: uma análise a partir do uso do mapa mental como recurso metodológico. In: SILVA CN, Caetano VNS, Oliveira Neto AC. Ensino de geografia e representação do espaço geográfico. Belém: GAPTA/UFPA; 2013, p. 205-230

11. LIMA MVC, Costa SMG. Cartografia social das crianças e adolescentes ribeirinhas/quilombolas da Amazônia. In: Silva CN, Caetano VNS, Oliveira Neto AC. Ensino de geografia e representação do espaço geográfico. Belém: GAPTA/UFPA; 2013, p. 255-290.

12. Silva CN. A representação espacial e a linguagem cartográfica. Belém: GAPTA/UFPA; 2013.

13. Silva CN, Silva JMP, Chagas CAN, Castro CJ. Qualificação profissional e a informação espacial: o Laboratório de Análise da Informação Geográfica (LAIG) em atividades de capacitação. In.: Ferreira CES, Lima e Silva JC, Cruz PRS, Passos SC. Geografia, gestão e segurança ambiental. Belém: GAPTA/UFPA; 2014, p. 11-26.

14. Joly F. A cartografia. Campinas: Papirus; 1990.

15. Oliveira C. Dicionário cartográfico. Rio de Janeiro: IBGE; 1983.

16. Moura Filho J. Elementos da cartografia: técnica e histórica. Belém: Falangola; 1993.

17. Almeida GP, Ventorini SE. Mapeamento participativo de áreas de risco a movimento de massa no bairro Senhor dos Montes - São João Del-Rei, MG. Caderno de Geografia, v.24, número especial (1); 2014, p. 79-93. 